\title{
Role of Information Systems in Customer Relationship Management
}

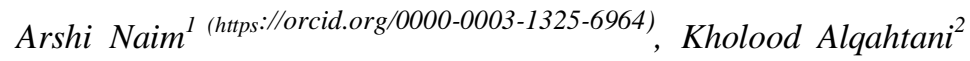

Department of Information Systems, King Khalid University, Abha, KSA

arshi@kku.edu.sa1',kaljbar@kku.edu.sa ${ }^{2}$

\begin{abstract}
Applications of Information System (IS) have been instrumental in achieving Customer Relationship Management (CRM). Decision Support Systems (DSS) is an IS application that aids in decision making processes for many business concepts and CRM is one of them. CRM depends on firm's tasks for developing and retaining customers while achieving their satisfaction and enhancing sense of belongingness for their products and services. Profit maximization, process of customer value and building strategic values for the firm are the three empirical benefits of CRM that are achieved through analytical, operational, and direction capabilities respectively. This research focus on applications of DSS models for CRM at analytical, operational and directional level (AOD). Three online retail firms of KSA are referred as data source for the analysis of CRM by DSS models. The research determined how a customer-oriented firm uses DSS to attain CRM and profitability at three levels namely; Analytical, Operational and Strategic.
\end{abstract}

Keywords: Analytical, Customer Relationship Management, Decision Support Systems, Directional, IS, Operational, What if Analysis

\section{Introduction}

Customer relationship management (CRM) [1] is the branch of management that gives the scope of operational demonstration of relationship marketing and explains the characteristics of a customer, criterion and features for developing relationship between customers and firms, achieving customer loyalty and the ways of customers' retention. Firms apply CRM to explore prospects for their products and services, understand customer's requirements and their expectation for quality [1] [2]. CRM is particularly regarded as the firm's efforts to develop and retain customers through increased satisfaction and loyalty. DSS-based CRM systems have been applied in many business areas, and $R \& D$ is continuing to contribute to its expansion [3].

IS application is a collection of interrelated elements that work collaboratively to convert data into information that is used to support various organizations activities including control, planning, forecasting, decision making, coordination, and operational activities [4][5] and DSS is one of its important application that helps in the above tasks and besides, DSS can help organization's employees and managers in visualizing complex subjects, create new products, and problems analysis. Nowadays IS applications in the business area that can be categorized into different types such as support of business operations or support of managerial decision making [6]. Any ideal organization applies six major applications of IS such as Transaction Processing System (TPS), Office Automation System (OAS), Knowledge Work System (KWS), Management Information System (MIS), Executive Support System (ESS), Decision Support System (DSS) [7] [8] [9]. Figure 1 shows the types and basic information about the IS applications. 


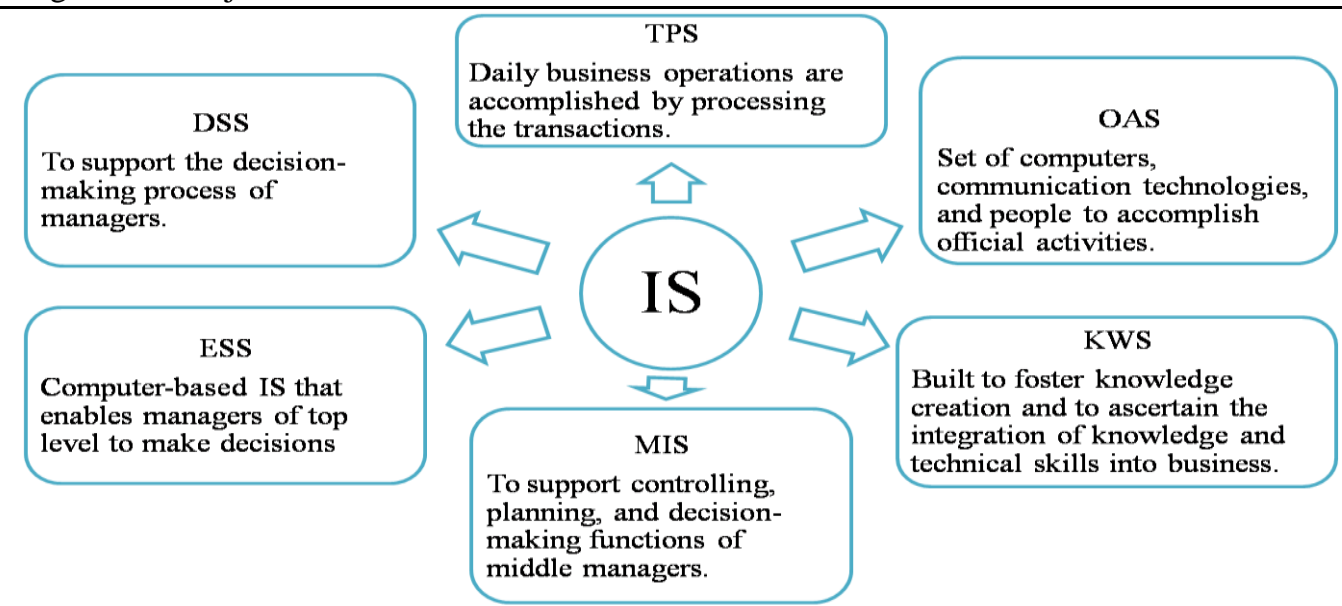

Figure 1. Types of IS Applications [9]

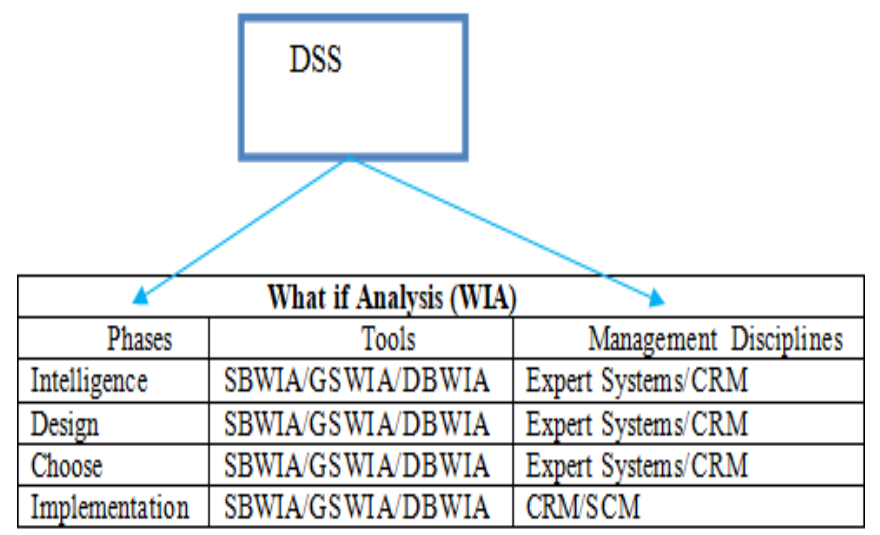

Figure 2. DSS (WIA) supporting the decisions [12]

This research is based on the application of (WIA) which is the DSS model-based analysis for three levels of (AOD) of CRM. DSS (WIA) is a computer-based application aiding in the decision making process for management related areas such as SCM, ERP, CRM, etc. (WIA) aids CRM in managing customers' inquiries and also in attracting, retaining, developing, and identifying customers and figure 2 gives a framework of DSS (WIA) for how decisions are supported for different management decisions [9][10]. This research paper is segmented into six parts; the first part gives an introduction and the second part covers the historical aspects of concepts used in this paper and previous studies showing the contribution of DSS (WIA) in management in general and specifically in CRM. The third part gives the details on conceptual hypothesis and Research methodology, the fourth part covers the major explanation of the research procedure and implications in Discussion. In the fifth and sixth part results and findings are illustrated followed by a conclusion. This research paper shows the application of DSS (WIA) in customer-oriented firms at three levels (AOD) for achieving profit and building relationships and eventually impacting CRM by the use of hypothetical data.

\section{Literature Review}

Before the 1960s, the IS role was simple, basically, were used to achieve the goals of electronic data processing (EDP), such as accounting and transaction processing. EDP is defined as the use of a computer to perform various processes on data including summarizing, classifying, manipulating, and recording. EDP is also called transaction processing systems (TPS) [10] [14].

In the 1960s, other functions were added to IS which were for processing of data into useful informative 
reports, and MIS was therefore introduced. MIS gave new roles to the managers, they started to use IS for making decisions and developing business applications with the IS contribution [10] [14].

By the 1970s, the IS reports produced by MIS were not enough to satisfy the management decision-making needs that were when (DSS) emerged and it provided computer-based interaction and specialized support for managers and end-users to facilitate decision-making processes [11] [15]. End users now could support their job requirements by using their own computing resources; they did not need to wait for a centralized corporate information services department to provide indirect support. In later years EIS [13] and AI were techniques introduced with different advantages and scope. ES and KMS gave a new role to IS in the late 90s and 1990 ERP emerged for corporate resource planning and allocation [13][15]. In the same era, internet growth started that gave a new significance to all the IS applications and DSS applications became very popular in the decision making process in management systems particularly for CRM [10] [14] [16].

Past researches have shown how firm's use CRM for motivating their employees to essentially develop customer-focused thinking [16] and here IS has played an important role as a technology solution. In the past, researchers have focused on methods of IS affecting customer-oriented firms for CRM profitability and also formulated models such as the CRM profitability model from relationship marketing and system efficiency perspective [15] [16] [17].

Previous studies have shown the importance of using software applications and technology for different types of management disciplines such as SCM, ERP, or CRM, but the expected results for CRM are not achieved because of its qualitative nature. However, CRM continued to apply IS applications for various purposes and identified different impact factors of IS applications for different levels of CRM but DSS is one application found to be most effective working for the achievement of CRM objectives [15] [16] [17]. Previous studies have shown the relationship of DSS for CRM but this research paper gives an analysis of the application of DSS (WIA) for showing the results for CRM at all three levels and suggests the same model for any customer-oriented firms for their applications [18].

Previous studies have argued that in many firms the most clear methods to implement CRM is through the use of software applications or technology in the form of electronic customer relationship management technology, however, CRM systems promise much but often fail to deliver the expected benefits; in CRM activities, a customer-oriented firm will integrate their service process to create their target and market strategy. Although the widespread acceptance of this relationship is evident in the growing popular literature on customer-oriented and information system success models, it is not yet clearly understood why and how CRM becomes successful while others fail.

On the other hand, research has argued that CRM is essential for the firm to create an environment where employees are motivated to be customer-focused in their thinking, IS becomes the facilitation point for cross-functional technology solutions and a catalyst for business process improvements within a company, business process improvement that assures efficiency and excellence of enterprise operations is also considered in the concept of CRM, and new business processes are required to achieve more effective and closer interactions with customers.

The research goal was to determine how a customer-oriented firm uses information systems to affect the CRM profitability. In this study, we formulated the CRM profitability model from relationship marketing and system efficiency perspective.

Research also presents the dependence of ISM with CRM for building brand image, increasing sales, strategic planning but this research paper also covers the aspects of ISM for CRM and how both can be considered for providing the research findings. 


\section{Research Methodology}

CRM provides its services to firms at three levels; Analytical, Operational, and Directional levels (AOD), and each level benefits the firm in some way that eventually contributes to achieving CRM. (WIA) facilitates in building these levels and offers decision-making solutions to structured, semi-structured, and unstructured decisions for these levels. Figure 3 depicts the research framework used for this paper.

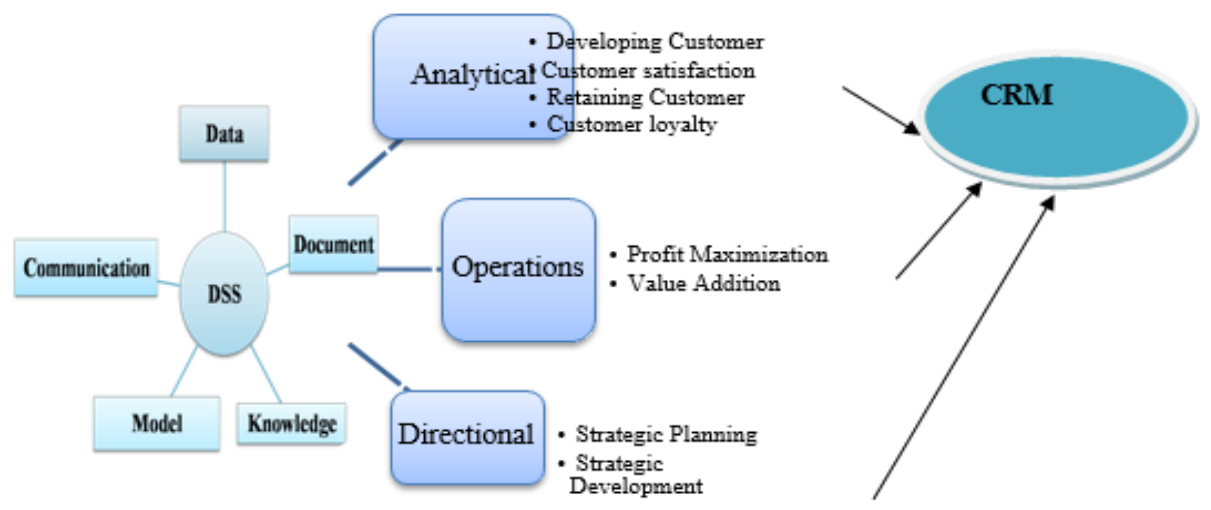

Figure 3. Research Framewor showing the role of WIA in CRM

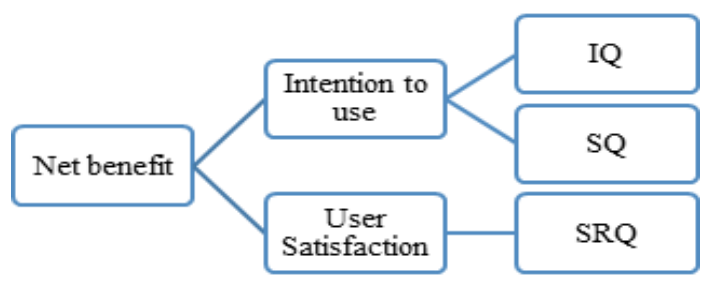

Figure 4. ISM by Delone and McLean [19]

Three hypothetical examples are taken for showing the results, DSS decision-making models are applied to these three examples for all three CRM's levels and results are analyzed from (WIA) applications. The results are measured for three levels (AOD) by (WIA) and show its impact on CRM. To understand how the information from these three examples can be helpful for CRM, Delone, and McLean's perspective of ISM can be referred [19]. The ISM has been treated as a major issue of management research for any type of service for measuring satisfaction. DeLone and McLean have taken six major categories of measures of IS application like DSS success which are seen to form an integrated whole [19]. These measures are System Quality (SQ), Information Quality (IQ), Service Quality (SRQ), resulting to use and user satisfaction and finally to individual impact, and organizational impact and all these measures are a subpart of three levels (AOD) of CRM [19]. IQ, SQ, and SRQ measure A, SQ, and SRQ measure O, and SRQ measure D. Figure 5 depict how ISM is used in our study for preparing the criteria for measuring AOD. These criteria are used as inputs for decision-making processes by (WIA) based such as Scenario-based, Goal seeking, and Data-based for CRM. These criteria and information are extracted from the hypothetical data for three examples submitted for different services for three months (from March to May 2020) and show how the target of CRM can be achieved in the next month June 2020 for all three AOD levels using a classification of Information Success model. 

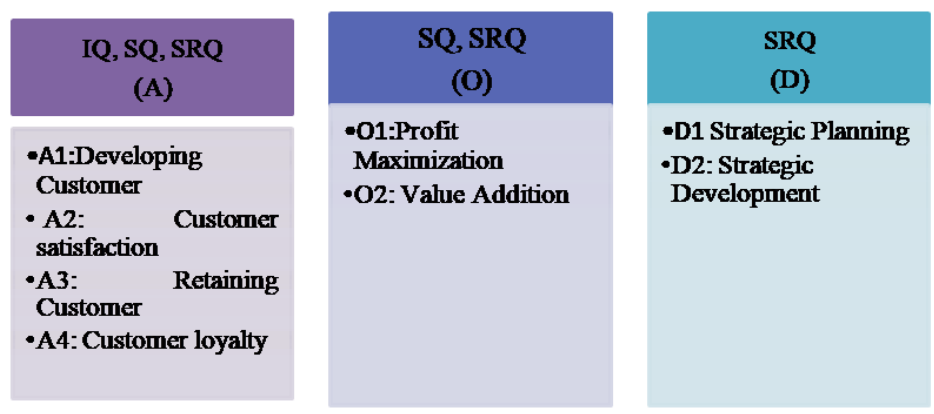

Figure 5. Criteria for ISM for (AOD)

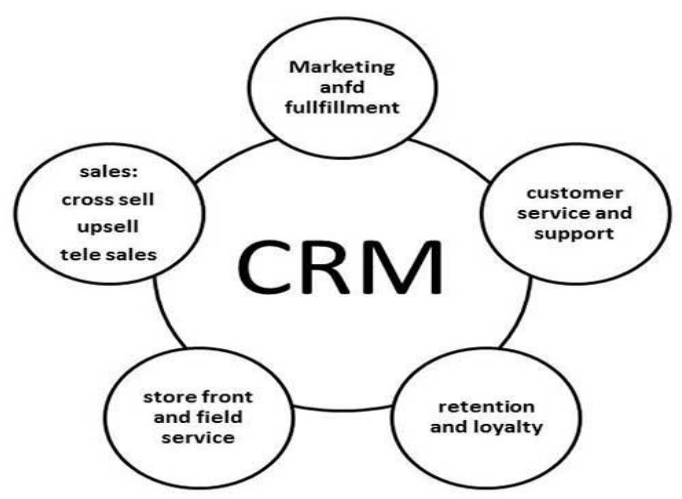

Figure 6. CRM scope [16]

\section{Discussion}

Most of the service-oriented firms focus on achieving CRM by having customer interaction and creating an opportunity for increasing satisfaction level, improving retention, increasing revenue or profit, attain brand loyalty, strengthen brand value, etc. CRM helps service firms in particular and all other businesses, in general, to optimize customer relationships by integrating at the AOD level. The CRM Advantages for customer-oriented firms: CRM reduces the time and cost to deploy integrated advantages with a comprehensive set of solutions based on the principles of services and types of levels. These benefits help inefficient business operations, receiving updated and accurate information, vision for successful business applications [23]. Figure 6 gives the scope of CRM for customer-oriented firms that cover five major areas explained in the previous part of the paper. (WIA) provides computer-aided decision-making solutions to CRM for (AOD) and helps in getting the following key benefits. Below given table 1 gives the key benefits that can be received by the CRM with an application of (WIA).

Table 1: DSS (WIA) Solutions to CRM Key Benefits

\begin{tabular}{|l|l|}
\hline \multirow{3}{*}{ DSS (WIA) offering solutions to CRM } & \multicolumn{1}{|c|}{ Key Benefits Achieved } \\
\cline { 2 - 3 } & Identify Customer's Preferences \\
\cline { 2 - 3 } & Integrate all Management Services \\
\cline { 2 - 2 } & $\begin{array}{l}\text { Increase Productivity and Revenue by Providing } \\
\text { Customer Vision }\end{array}$ \\
\cline { 2 - 2 } & Achieving Customer Satisfaction and Retention \\
\cline { 2 - 2 } & Strengthen Brand Image and increase Brand loyalty \\
\hline
\end{tabular}




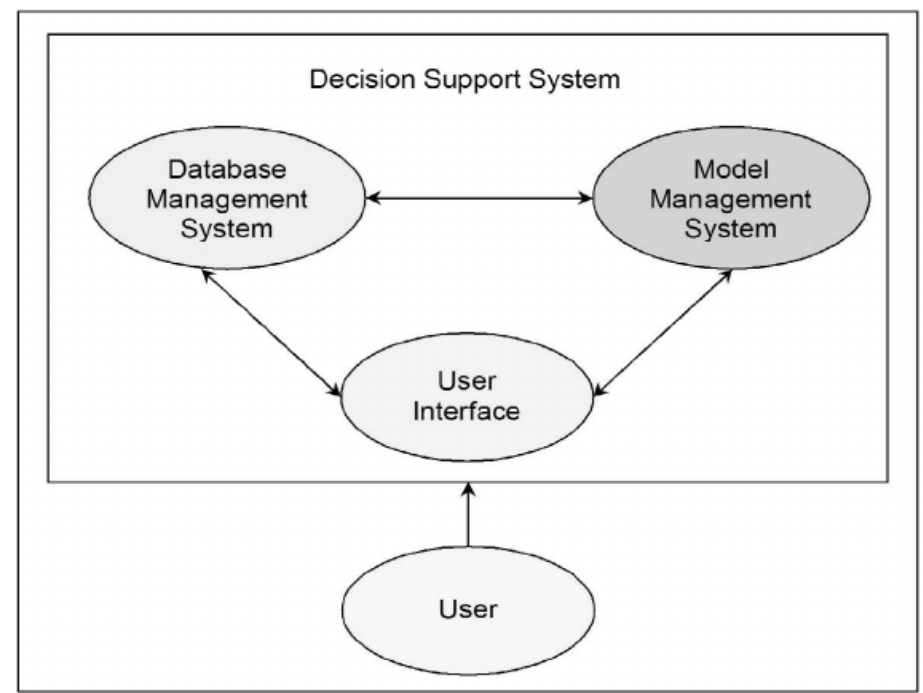

Figure 7. DSS (WIA) Framework for User Interface [24]

DSS (WIA) offers the advantages to CRM and that results in many benefits to the firm in general such as achieving competitive advantages, identifying business opportunities, receiving quick customers' responses, increasing sales, knowing demand value and customers' expectations. Figure 7 shows the framework of DSS (WIA) that can be applied for user interfaces for receiving users' reviews and expectations by its three types. There are two types of DSS namely, data-based DSS, and model-based DSS. (WIA) is a model-based DSS and below given figure 8 shows the basic types of DSS [20] [21] [22].

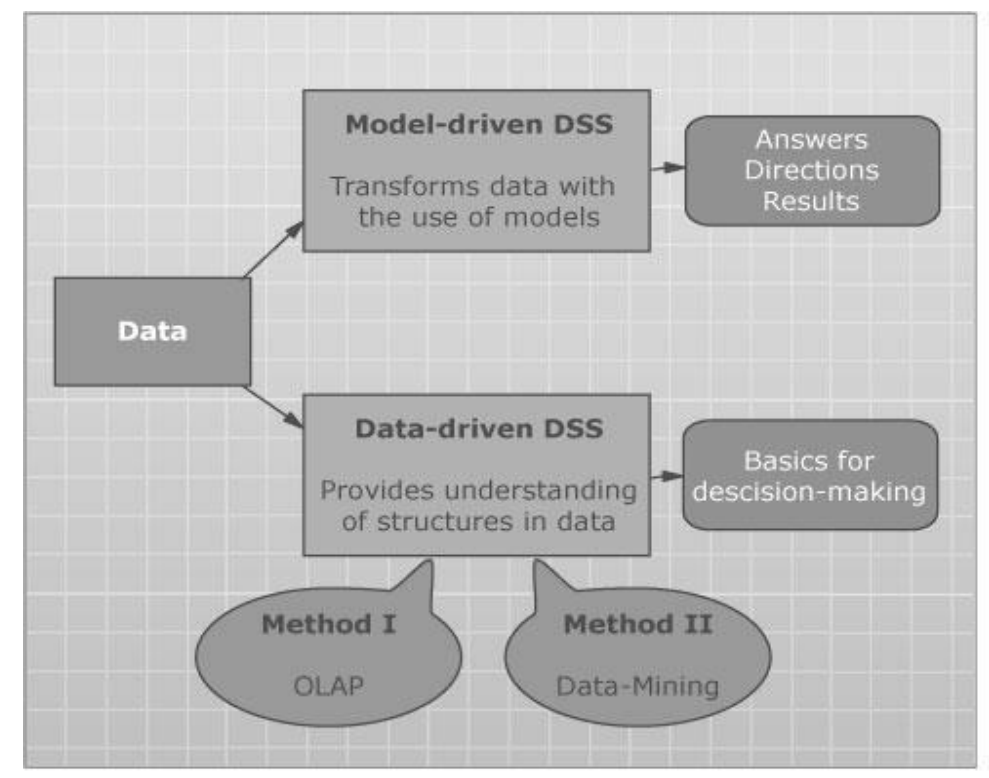

Figure 8.Types of DSS [25] [26] 


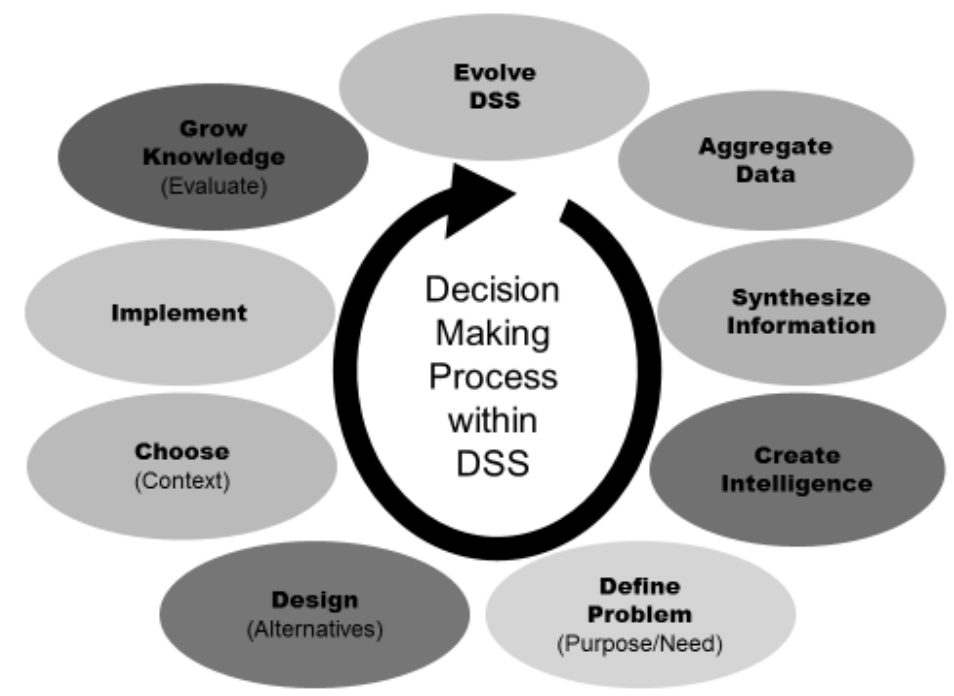

Figure 9.DSS Decision Making Process within [26]

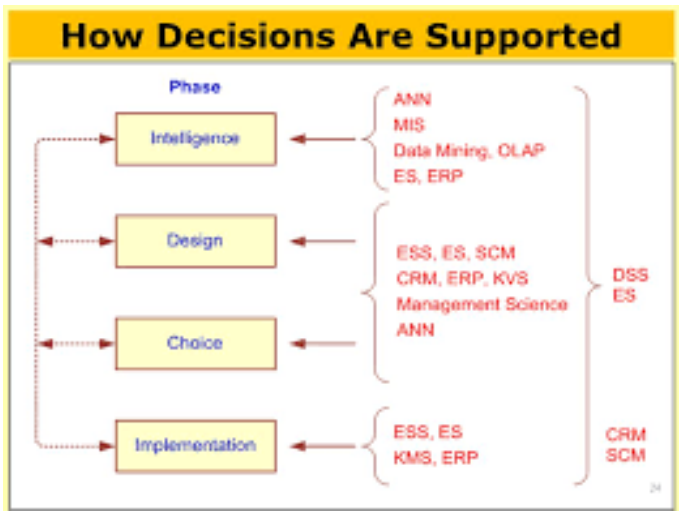

Figure 10.DSS supporting other Systems in various phases [26]

\section{Research Procedure}

General scenario: Three sets of criteria are developed for each level as mentioned in figure 5, referring to these criteria hypothetical data for three examples are created and categorized in the DSS framework to find out how DSS (WIA) can facilitate the decision-making process from structure to unstructured for each CRM. It is important to notice that (WIA) makes only recommendations not the results in absolute terms; it facilitates the decision-making process but does not force to implementation of a particular scenario. As mentioned above there are three types of (WIA); Scenario based (SBWIA), Goal Seeking (GSWIA), and Data-Based (DBWIA), for the three levels of CRM aligned with Information success models, all three types of (WIA) can be implemented for showing its impact on CRM. Below given tables below show the three Examples for three levels (AOD) aligned for the information success model, criteria used by three different types of (WIA). Table 2 shows the analytical scenario for the conditions with WIA and without WIA under the categoeis of A1, A2, A3, A4, and the firm strives for higher growth for each criterion after applying WIA. The firm can use SBWIA and while elaborating the target for each criterion and set a scenario to achieve that. Below given tables 2,3 and 4 show the three online retail firms for three levels (AOD) aligned for information success model, criteria used by three different types of what if analysis. With WIA is represented by the plus symbol and with WIA is representd by the minus symbol. For the puspose of privacy of data, names of the online retails firms are 
International Journal of Intelligent Communication, Computing and Networks

Open Access Journal (ISSN: 2582-7707)

https://doi.org/10.51735/ijiccn/001/37

not disclosed. The data is collected for the year 2020 .

Table 2: Analytical by SBWIA

\begin{tabular}{|l|l|l|l|l|l|l|}
\hline \multirow{3}{*}{ Criteria } & \multicolumn{6}{c|}{ IQ, SQ, SRQ (A) [ Analyzed by SBWIA] } \\
\cline { 2 - 8 } & A & \multicolumn{7}{c|}{ B } & \multicolumn{2}{c|}{$C$} \\
\cline { 2 - 8 } & + & - & + & - & - \\
\hline A1:Developing Customer & 5000 & 3500 & 3000 & 1500 & 2500 & 1500 \\
\hline A2:Customer Satisfaction & 5000 & 3500 & 3000 & 1500 & 2500 & 1500 \\
\hline A3: Retaining Customer & 5000 & 3500 & 3000 & 1500 & 2500 & 1500 \\
\hline A4: Customer loyalty & 5000 & 3500 & 3000 & 1500 & 2500 & 1500 \\
\hline
\end{tabular}

Table 3 depicts the profit for the for three online retail firms and by using DBWIA, the firm can predict $\mathrm{O} 1$ and $\mathrm{O} 2$ while using DBWIA. These numbers are shown in sales and DBWIA helps in manipulating data for achieving the target sales. Table 3 also shows the variation as an increase and decrease in profit and value addition that usually occur in real situations so how DBWIA facilitated in predicting the Operational level CRM for all the criteria O1 and O2. It is important to mention that DBWIA at the operational level only provides values for prediction but possible decision-making analysis has to be conducted through SBWIA or GSWIA.

Table 3: Operation by DBWIA

\begin{tabular}{|c|c|c|c|c|c|c|}
\hline \multicolumn{7}{|c|}{ SQ, SRQ (O)[Analyzed by DBWIA] } \\
\hline \multirow[t]{3}{*}{ Criteria } & \multicolumn{6}{|c|}{ Online Retail firms 2020} \\
\hline & \multicolumn{2}{|r|}{ A } & \multicolumn{2}{|r|}{$\mathrm{B}$} & \multicolumn{2}{|r|}{$\mathrm{C}$} \\
\hline & + & - & + & - & + & - \\
\hline O1:Profit Maximization & 5000 & 3500 & 3000 & 1500 & 2500 & 1500 \\
\hline O2: Value Addition & 5000 & 3500 & 3000 & 1500 & 2500 & 1500 \\
\hline
\end{tabular}

Table 4: Directional by GBWIA

\begin{tabular}{|l|l|l|r|r|r|r|}
\hline \multirow{3}{*}{ SRQ (D) [Analyzed by goal seeking What if Analysis] } \\
\hline & \multicolumn{5}{|c|}{ Online Retail firms 2020 } & -2023 \\
\cline { 2 - 7 } & \multicolumn{2}{|c|}{ A } & \multicolumn{3}{c|}{ B } & \multicolumn{2}{c|}{ C } \\
\cline { 2 - 7 } & + & - & - & + & - \\
\hline D1: Strategic Planning & 5000 & 3500 & 3000 & 1500 & 2500 & 1500 \\
\hline D2: Strategic Development & 5000 & 3500 & 3000 & 1500 & 2500 & 1500 \\
\hline
\end{tabular}

Table 4 shows the directional level in CRM explains the strategic achievement for the products, services, and policies of the form in general. Usually, Directional level CRM focuses on short to long-term achievements, table 4 shows two criteria such as D1 and D2 at Directional level CRM and measured by GSWIA. Goals are set for 2020-23 and analyzed from 2020 for criteria D1 and D2 for three online retial firms. Usually, data set for this level can be extracted from sales inferred through brand effectiveness or brand image. Data collected from these examples are analyzed by (WIA) for decision making for achieving CRM for all these three levels and recommendations are made in the results section. (WIA) suggests which area is weak and the firm's need to concentrate on changing their strategies for meeting their goals. In above given three examples (WIA) stresses the prompt changes with minimum efforts and also provides assumptions for 
International Journal of Intelligent Communication, Computing and Networks

Open Access Journal (ISSN: 2582-7707)

https://doi.org/10.51735/ijiccn/001/37

future improvements and meeting the target for all three levels for CRM. (WIA) is applied at three levels and presents how targets can be met by supporting strongly the tools of decision-making processes. From the above given three examples in tables 2, 3, and 4 customer-oriented firms can refer (WIA) for AOD and can achieve the following benefits specified as criteria for AOD in CRM and ISM. Below given table 5 gives a comprehensive view and derived benefits from interrelationships between CRM, ISM, AOD, and (WIA).

\section{Results}

The study covers the application of (WIA) for CRM for three levels of AOD using ISM. This study is based on data set collected from online resouces for three online retail firms that tried to explain how the DSS model-based can help in CRM for AOD. Above given tables show the varioations at all three levels of AOD for the sales. WIA has facilitated all three firms to have increase in sales, better strategic planning and achieving customer satisfaction after applying WIA. For firm $\mathrm{C}$ drastic improvement is observed after applying WIA and for firms A and B good improvement is noticed. There are many benefits for using WIA and Table 5 shows the benefits of using WIA for three firms A, B and C.

Table 5: Derived Benefits from (WIA) models for AOD

\begin{tabular}{|c|c|c|}
\hline CRM level and ISM & $\begin{array}{l}\text { DSS Model based } \\
\text { What if Analysis }\end{array}$ & Benefits Achieved \\
\hline IQ, SQ, SRQ (A) & \multirow{5}{*}{$\begin{array}{l}\text { [Analyzed by } \\
\text { SBWIA] }\end{array}$} & \\
\hline $\mathrm{A} 1$ :Developing Customer & & Customer Orientation (CO) \\
\hline A2:Customer satisfaction & & $\begin{array}{l}\text { Information Quality } \\
\text { (IQP) }\end{array}$ \\
\hline A3:Retaining Customer & & Value addition in Services (VAS) \\
\hline A4: Customer loyalty & & $\begin{array}{l}\text { Supporting customers and } \\
\text { Grievance handing. (SCGH) }\end{array}$ \\
\hline SQ, SRQ (O) & \multirow{3}{*}{$\begin{array}{l}\text { [Analyzed by } \\
\text { DBWIA] }\end{array}$} & \\
\hline O1:Profit Maximization & & Achieving profit through sales (PS) \\
\hline O2: Value Addition & & Value addition in Services (VAS) \\
\hline SRQ (D) & \multirow{3}{*}{$\begin{array}{l}\text { [Analyzed by } \\
\text { GSWIA] }\end{array}$} & \\
\hline D1: Strategic Planning & & $\begin{array}{l}\text { Enhancing brand value and } \\
\text { increase systems efficiency (SE) }\end{array}$ \\
\hline $\begin{array}{l}\text { D2: Strategic } \\
\text { Development }\end{array}$ & & $\begin{array}{l}\text { Performance based policies for long } \\
\text { run and offer systems support } \\
\text { (SSP) }\end{array}$ \\
\hline
\end{tabular}

$\mathrm{CO}$ refers to the commitment of the firm to identify and satisfy customer concerns and develop more customers through providing quality services. SBWIA gives the situation like quality for longer period of time and meet demand for new services about the quality and measures if more customers are developed for the particular services or not, SBWIA facilitates at A level of CRM to measure if customers are satisfied or not for that SBWIA creates a scenario for customers related to quality, reliability of information and after sales services as well then make a target for achieving it after implementation of this scenario. Customer retention is the results of customer satisfaction which can be achieved through values added services, technology has played a great role in adding values and increasing retention rate, SBWIA creates a scenario for the past data for customer retention rate and based on that gives the variation from the expected retention target. To achieve customer loyalty, there are many factors to be considered by CRM; therefore scenario for A4 needs to refer many dimensions such as providing services of good quality on time, listening to the customer complaints, their reactions and eventually attaining customers' loyalty. There are some philosophies that give a direct relation between customer reactions to customer loyalty in relation to CRM performance for identifying the scenario for A4, SBWIA considers many few 

the utilization experience with the product or service. As customer loyalty is commonly acknowledged as one of the most useful measurements of level A of CRM as it measures profitability, satisfaction and retention. At the operational level of CRM and from an ISM perspective, business process improvement that assures efficiency and excellence of enterprise operations is an important to be measured, therefore DBWIA is used to analyze previous months' sales and revenue and based on past trends predict the future sales and revenue for the firms. In this analysis CRM needs DSS model based approach for marketing, sales and earning maximum profits for the firm. ISM and CRM work together at D level to build strategic planning for the firm where the major focus is brand loyalty, building brand image and strengthening the brand therefore GSWIA is the best DSS model to be implemented which sets the target and then make a plan for achieving it. GBWIA helps in decision making process and make possible recommendations for variations. Example-3 in table 4 shows how data at D1 levels are aided by GSWIA for the successful of strategic planning. This process included many predetermined goals, parameters such as cost, time, function and efficiency in which they should be achieved. The assumption on which GSWIA works for D1 is that the relationships between CRM efficiency and customer reaction are managed by all CRM activities like customer reaction, perception, loyalty, retention and all contribute in strategic planning. D2 level of CRM is measured by GSWIA by measuring the performance of the firms based on what strategies were developed to attain that level. Also GSWIA studies the previous data for D2 and identifies that successful strategies bring more profits to the firm and contribute in customer satisfaction. Firms use GSWIA to measure of the D2 CRM for systems performance and assume if the system has been implemented and adopted successfully all criteria such as resource utilization; reliability, response time, and ease of terminal use; data accuracy, reliability, completeness, system flexibility, and ease of use; consistency of the user interface, quality of documentation, and sometimes, quality and maintainability be able to reap its benefits. The results show the high degree of relevance and dependence on (WIA) for three examples. DBWIA can help firms to know the areas where they need to work to achieve the target value that will result in achieving level O of CRM.

\section{Conclusion}

CRM is one of the most important areas in management and DSS (WIA) is one of the relevant methods for the decision-making process. This research presents a general scenario for any customer-oriented firm for using (WIA) impacting CRM where this model facilitates in developing customer satisfaction, retention, loyalty and also to contribute in sales and revenue along with the measuring the effectiveness of strategic planning for future growth. Three online retail firms present the bebefits of using WIA for three levels; AOD and at all levels good improvement is seen for all the three firms. The research suggests to compare more customer oriented firms' results for other marketing related practices especialy during COVID: 19 panadamic.

\section{References}

1. Raab, G., Ajami, R. A., \& Goddard, G. J. (2016). Customer relationship management: A global perspective. CRC Press.

2. Peppers, D., \& Rogers, M. (2004). Managing customer relationships: A strategic framework. John Wiley \& Sons.

3. Chan, S. L., \& Ip, W. H. (2011). A dynamic decision support system to predict the value of customer for new product development. Decision support systems, 52(1), 178-188. 
International Journal of Intelligent Communication, Computing and Networks

Open Access Journal (ISSN: 2582-7707)

https://doi.org/10.51735/ijiccn/001/37

4. Grover, V., Chiang, R. H., Liang, T. P., \& Zhang, D. (2018). Creating strategic business value from big data analytics: A research framework. Journal of Management Information Systems, 35(2), 388-423.

5. Filip, F. G. (2020). DSS - A Class of Evolving Information Systems. In Data Science: New Issues, Challenges and Applications (pp. 253-277). Springer, Cham.

6. Appelbaum, D., Kogan, A., Vasarhelyi, M., \& Yan, Z. (2017). Impact of business analytics and enterprise systems on managerial accounting. International Journal of Accounting Information Systems, 25, 29-44.

7. Pavoine, S., Vallet, J., Dufour, A. B., Gachet, S., \& Daniel, H. (2009). On the challenge of treating various types of variables: application for improving the measurement of functional diversity. Oikos, 118(3), 391-402.

8. Kaiser, R., Spiegel, P. B., Henderson, A. K., \& Gerber, M. L. (2003). The application of geographic information systems and global positioning systems in humanitarian emergencies: lessons learned, programme implications and future research. Disasters, 27(2), 127-140.

9. O'brien, J. A., \& Marakas, G. M. (2005). Introduction to information systems (Vol. 13). New York City, USA: McGraw-Hill/Irwin.

10. Arnott, D. (2004). Decision support systems evolution: framework, case study and research agenda. European Journal of Information Systems, 13(4), 247-259.

11. Watson, H. J. (2018). Revisiting Ralph Sprague's framework for developing decision support systems. Communications of the Association for Information Systems, 42(1), 13.

12. Aronson, J. E., Liang, T. P., \& MacCarthy, R. V. (2005). Decision support systems and intelligent systems (Vol. 4). Upper Saddle River, NJ, USA:: Pearson Prentice-Hall.

13. Sharkey, U., \& Acton, T. (2012). Innovations in information systems from transaction processing to expert systems.

14. Polkowski, L., Tsumoto, S., \& Lin, T. Y. (Eds.). (2012). Rough set methods and applications: new developments in knowledge discovery in information systems (Vol. 56). Physica.

15. Jia, P., Cheng, X., Xue, H., \& Wang, Y. (2017). Applications of geographic information systems (GIS) data and methods in obesity-related research. Obesity reviews, 18(4), 400-411.

16. Sigala, M. (2018). Implementing social customer relationship management. International Journal of Contemporary Hospitality Management.

17. Naim, A., \& Alahmari, F. (2020). Reference model of e-learning and quality to establish interoperability in higher education systems. International Journal of Emerging Technologies in Learning (iJET), 15(2), 15-28.

18. Naim, A., Khan, M. F., Hussain, M. R., \& Khan, N. (2019). "Virtual Doctor" Management Technique in the Diagnosis of ENT Diseases. JOE, 15(9), 88.

19. Naim, A. (2020). Realization of diverse Electronic tools in learning and teaching for students with diverse skills. Global Journal of Enterprise Information System, 12(1), 72-78.

20. Naim, A., \& Bashir, A. (2016). Application of Quality Matters Standards on Supportive and Online Module in Higher Education Program. Research Revolution, 5(3), 6-12.

21. Watanabe, C., \& Hobo, M. (2004). Co-evolution between internal motivation and external expectation as a source of firm self-propagating function creation. Technovation, 24(2), 109-120.

22. Alt, R., \& Puschmann, T. (2004, January). Successful practices in customer relationship management. In 37th Annual Hawaii International Conference on System Sciences, 2004. Proceedings of the (pp. 9-pp). IEEE.

23. Delone, W. H., \& McLean, E. R. (2003). The DeLone and McLean model of information systems success: a ten-year update. Journal of management information systems, 19(4), 9-30.

24. Foss, B., Stone, M., \& Ekinci, Y. (2008). What makes for CRM system success-Or failure?. Journal of Database Marketing \& Customer Strategy Management, 15(2), 68-78. 
25. Cuthbertson, R., \& Laine, A. (2003). The role of CRM within retail loyalty marketing. Journal of Targeting, Measurement and Analysis for Marketing, 12(3), 290-304.

26. Collins, K. (2001). Analytical CRM: Driving Profitable Customer Relationships. Strategic Planning.

27. Friday, D., Ryan, S., Sridharan, R., \& Collins, D. (2018). Collaborative risk management: a systematic literature review. International Journal of Physical Distribution \& Logistics Management.

28. Eom, S. (2020, May). DSS, BI, and Data Analytics Research: Current State and Emerging Trends (2015-2019). In International Conference on Decision Support System Technology (pp. 167-179). Springer, Cham.

29. Rupnik, R., \& Kukar, M. (2007). Decision support system to support decision processes with data mining. Journal of information and organizational sciences, 31(1), 217-232.

30. Asemi, A., Safari, A., \& Zavareh, A. A. (2011). The role of management information system (MIS) and Decision support system (DSS) for manager's decision making process. International Journal of Business and Management, 6(7), 164-173.

31. Naim, A., Alahmari, F., \& Rahim, A. (2021). Role of Artificial Intelligence in Market Development and Vehicular Communication. Smart Antennas: Recent Trends in Design and Applications, 2, 28. 